Article

\title{
Death Row Confinement and the Meaning of Last Words
}

\author{
Robert Johnson *, Laura Caitlin Kanewske and Maya Barak \\ Department of Justice, Law and Criminology, American University, 4400 Massachusetts Avenue, \\ Washington, DC 20016, USA; E-Mails: lk0784a@student.american.edu (L.C.K.); \\ maya.p.barak@gmail.com (M.B.)
}

* Author to whom correspondence should be addressed; E-Mail: robert.johnson@american.edu; Tel.: +1-202-885-2951.

Received: 20 January 2014; in revised form: 1 February 2014 / Accepted: 7 February 2014 /

Published: 17 February 2014

\begin{abstract}
Life under sentence of death can be a transformative process. One measure of this transformation can be found in last words, which often highlight the humanity of condemned prisoners on the threshold of execution, in sharp contrast to popular conceptions of these prisoners as evil, remorseless, and irredeemable. Our reading of last words suggests that the transformation process can be best understood by examining the dominant contours of the death row experience, the most recent formative experience in the lives of condemned prisoners before they are put to death.
\end{abstract}

Keywords: last words; executions; death row

\section{Introduction}

The opportunity for condemned prisoners to speak their last words is an enduring element of the execution process. Last words were a part of the execution process in England as early as 1388; the practice was brought to the Americas by Puritan colonists in the early 17th century ([1], p. 1160). The ritual of last words has persisted to this day in the American context and is viewed as a de facto right of the condemned. Remarkably, last words have even been afforded to such stigmatized persons as witches, slaves, prisoners of war, and victims of lynch mobs ([1], p. 1160). Most recently, last words have been described as "the existential centerpiece of executions", potentially humanizing the offender by offering a positive meaning to the execution as the culmination of his or her life ([2], p. 112). Last words may also serve to humanize the modern death penalty. With the exception of last words and 
perhaps last meals [3,4], modern executions are relentlessly impersonal-entailing years of human warehousing of the condemned on death row and culminating in the efficient disposal of the prisoner after execution in the death chamber [5-7].

The meaning and significance of last words are the subjects of considerable historical and contemporary research. Our concern is with contemporary executions, but it is worth noting that accounts of public executions in times past offered differing portraits of the last words of the condemned. The dominant view for many years was that the condemned man or woman, on the scaffold and in many cases soon to be tortured, spoke with eloquence, admitting guilt and forgiving the executioner and the community for the violent, indeed often spectacularly brutal justice about to be carried out [8,9]. Alternative accounts, however, both in Europe and America, feature the condemned in the throes of terror, shaking, often mute, even soiling themselves in fear of what is to come [10]. Since much of the early evidence on calm, cooperative condemned men and women cited in historical research came from media documents such as broadsheets, written for public consumption and distributed to the many citizens who were not able to attend executions, the prevailing view today is that gracious prisoners speaking eloquently on the public scaffold were the exception, not the rule [8]. The myth of the eloquent, contrite prisoner may have had a special resonance in times past because it made the execution a proper ceremony, one that conveniently reinforced the notions of justice in the larger community. The sheer existence of last words as part of modern executions lends an element of humanity to an otherwise impersonal and dehumanizing practice [3]; the content of last words has no special meaning in relation to the humanity or justice of these executions. In any event, the recording of last words for modern executions is more objective and hence more accurate-last words are not presented as entertainment but instead are dutifully recorded by officials.

\section{Last Words Today: What Prisoners Say}

Several studies focus on general themes adduced in the last words of inmates put to death in Texas, with sample sizes ranging from 237 [11] to 331 [12] last statements. ${ }^{1}$ In one of the earliest comprehensive studies of last words, Slone et al constructed a general typology of executed offenders in Texas, categorizing offenders into four broad but distinct types based on the content of their last words: contrite (33\% of cases); philosopher (16\% of cases); defiant (12\% of cases); and externalizer (10\% of cases) [13]. Similarly, Misshore and Bond determined that offender statements featured positive emotion significantly more often than negative emotion [14]. In a study using qualitative methodologies, Heflick identified six broad themes in the statements of Texas inmates executed between January 2007 and April 2005, many with positive connotations: love/appreciation of others

1 Texas inmates are the focus of this body of research because Texas executes a large number of prisoners, yielding a large sample for research. Moreover, the Texas Department of Criminal Justice makes the last statements, demographic and crime-related information of every offender executed in the state available through its website. All narrative themes, relationships, and insights identified by the following studies are thus derived from a specific population of executed inmates. The sheer number of people put to death in Texas, together with the sizeable proportion of all executed prisoners made up by this group, gives weight to the last words of Texas' condemned prisoners. We hope to examine the last words of prisoners from other states, which will allow us to more directly assess the generalizability of the existing body of research on last words. 
(especially significant others), forgiveness, afterlife belief, activism (particularly promoting social causes and advising family members), claims of innocence, and silence ([11], p. 329). Though Heflick does not quantify the frequency of these themes, he does report that many offender statements contained multiple and overlapping themes [11].

Lester and Gunn found nine content areas using a word count program: affective and emotion processes, positive emotions, positive feelings, discrepancy (words like should, would, could, etc.), references to others, past tense verbs, religion, physical states and functions, and sex and sexuality ([12], p. 299). Interestingly, the researchers found that while the similarities in last statements across ethnic groups outweighed the differences - as in all studies of last words, positive sentiments prevailedHispanic Americans' statements included the greatest degree of religious content while African Americans' included the least ([12], p. 299). This is surprising given the prominent role of religion in the lives of African Americans facing death or contemplating suicide ([12], p. 299, citing [15]). Furthermore, while African Americans and Hispanic Americans may be expected to express more negative emotions in their last statements due to discrimination in their dealings with the criminal justice system [12], no significant differences were found in the degree or frequency of negative emotions in the last statements of these ethnic groups and Euro-Americans ([12], p. 299). These similarities across ethnics groups may speak to the equalizing influence of death row, as all condemned prisoners in Texas spend the last years of their lives under conditions of isolation and deprivation that approximate solitary confinement [16].

Schuck and Ward, again examining a sample of nearly 300 last statements of offenders executed in Texas, were able to discern a general pattern or structure by which last statements were most commonly ordered: subject (offender directly references self); addresses relevant relationships (from closest to furthest); expresses internal feelings (love, hate); defines situation (responsibility, acceptance vs. innocence, political statement, denial); deals with situation (self-comfort, religion, wish/hope, forgiveness, self-blame vs. accusation, denial); and closure (amen, I'm ready, let's do this, etc.) ([17], p. 51). ${ }^{2}$ The researchers then undertook a detailed analysis of the individual texts within this framework, finding that all offender statements could be sorted into two broad categories: those in which guilt was accepted (the more prevalent), and those in which guilt was denied ([17], pp. 58-59).

Eaton and Theuer analyzed the concepts of apology and remorse in the statements of executed inmates from Texas' death row between December 1982 and August 2007 [18]. Noting that non-capital offenders often feel motivated to offer formal apologies as a means of reducing their sentence or gaining leniency ([18], p. 328), the authors examined whether condemned prisoners would offer apologies in the death house when there was no hope of a change in sentence ([18], p. 328). Citing experimental studies by Hodgins and Liebesking [19], Eaton and Theuer point out that, because offenders are more likely to act defensively as the severity of punishment increases_-offering excuses, refusing to take responsibility for the crime-those facing execution would be expected to offer excuses rather than apologies or regrets in their last words ([18], p. 330). Certainly there is little or no evidence of apology or regret before or immediately after capital trials, or early on during death row confinement [5]. Contrary to expectations, Eaton and Theuer found a relative absence of defensiveness

2 This structure has led one researcher to suggest that these statements "sometimes have the feeling of an Oscars ceremony speech, albeit a dark version of one” ([2], p. 115). 
in the last words of nearly one third of all studied offenders, who instead offered apologies, most of which were directed towards the victim's family ([18], p. 327). The authors postulate that these offenders are contrite because they wish to present an image of themselves as decent persons before they are put to death ([18], see also [2]). Finally, the researchers also found that demographic characteristics of offenders were not significantly related to the presence or absence of apologies in last statements [18].

Like Eaton and Theuer [18], Rice, Dirks, and Exline also found no statistically significant difference between those who did and did not make final statements based on offender demographic or case characteristics ([20], p. 307). The nearly 300 statements analyzed were more likely to contain conventional sentiments that suggest sensitivity to the concerns of victims (such as guilt and repentance) rather than expressions of innocence, pronouncements of capital punishment as unjust, or claims that the legal system is biased and unfair ([20], p. 309). As noted by the researchers, and by Eaton and Theuer [18], this finding is at odds with a great deal of reintegrative shaming research, which suggests that serious offenders develop of variety of barriers against feeling responsibility for their actions and go to considerable lengths to deny their guilt and find fault with the justice system, if not the entire world [21].

Perhaps the most enlightening finding of Rice et al.'s study, however, is that this preference for expression of victim-sensitive themes is heavily influenced by the presence of the victims' family at the execution ([20], p. 310). For instance, before homicide victims were allowed to attend executions in Texas (December 1982-January 1996), less than 6\% of offender statements expressed repentance, as compared to $41 \%$ in the years in which victims' families were allowed to attend executions ([20], p. 314). When controlling for confounding factors, inmates were found to be 17 times more likely to express repentance in their final statements in the years following the inclusion of witnesses selected to represent the victim at the execution-essentially the victim's loved ones ([20], p. 314). This finding draws attention to the potentially powerful role of contextual factors in the shaping of last words - in this instance, the composition of the witnesses, which now typically includes three audiences: persons selected by the state, by relatives of the victim, and by the condemned prisoner (see generally [22]).

\section{Interpreting Last Words: What Prisoners Mean}

In an attempt to more fully understand the last words of executed inmates, several interpretive theoretical frameworks have been advanced. One such theory is Terror Management Theory (TMT) $[11,17]$. TMT is derived from Becker's work concerning the common, if not universal, desire of human beings to deny their mortality [23], a fate typically viewed with dread [24,25]. TMT holds that human beings, motivated by the terror resulting from contemplation of their own demise, will engage in a variety of coping mechanisms, most prominently clinging to aspects of their lives that afford a comforting identity in the face of death, such as religion, ethnicity, gender, nationality, and political association ([17], p. 46).

Condemned inmates experience extreme mortality salience - they are aware of the exact date, time, place, and method of their deaths. As a result, they may be particularly disposed to fall back on comforting sources of identity as a means to deny or at least defuse feelings of intense fear 
surrounding imminent execution ([17], p. 46). Thus, inmates facing execution will likely seek to signify their cultural identity in their last statements by, for instance, offering religious assertions, or proudly claiming membership in an ethnic, racial, or socio-cultural group. Furthermore, in accordance with the morality salience hypothesis of TMT, which holds that the stressors of impending death will predictably impel an individual to want to retain, regain, or boost his or her self-esteem to ward off frightening feelings of vulnerability [26], inmates will likely use their last statements to portray themselves as strong persons of worth. Researchers in this tradition see this process as favoring positive identities, such as that of a moral, religious, or even redeemed person ([17], p. 49). That said, other identities that may be positive to the offender if not the larger society, such as that of outlaw, gang member, or victim of racial injustice who stands strong until the end, would logically serve the same ends. In any event, last statements can provide a means through which offenders are able to increase self-worth and exert a degree of control over a situation in which they are otherwise powerless ([17], p. 60).

As noted by Heflick, system justification theory may also provide a useful framework through which to interpret last words [11]. Hypothesizing that those facing conditions of great threat will seek to justify the social system in which they live ([11], p. 326), system justification theory anticipates that those most disadvantaged by a system will be the ones who show the most support for it. Jost, Fitzsimmons, and Kay further hypothesize that this ardent support grows from a desire by disadvantaged persons to justify their suffering [27]. When applied to death row, Heflick notes that prisoners facing imminent execution will justify the system of capital punishment, even though it is that very system that is poised to take their lives ([11], p. 326). This theory has also been used to explain the largely positive sentiments expressed in last words. In particular, system justification is used to explain the fact that the last words of many condemned prisoners support capital punishment even as they are about to be executed. In our view, these findings can be explained in other, more parsimonious ways. Condemned prisoners may support the death penalty because they see violence as a way of solving problems; many on death row, notably violent men, support the death penalty long before their death by execution is salient or even likely [5]. Also, the notion that suffering must stem from a legitimate source to be properly endured is a dubious one. The notion of suffering at the heart of Christianity, the major religious affiliation of prisoners on Texas' death row, hinges on an injustice and, indeed a wrongful execution. To suffer the slings and arrows of an unfair fate is presumably as ennobling, if not more ennobling, than suffering a fate that is just.

A third framework through which to interpret the last statements of executed inmates is McKendy's notion of narrative debris, which he used to interpret the language of inmates imprisoned for violent crimes ([28], p. 473). When asked to conceptualize themselves as autonomous moral actors, McKendy found that violent inmates who had themselves been victimized (most prominently during confinement in harsh prisons) provided narratives replete with "fragments, gaps, inconsistencies, false starts, pauses, switches between discourses, self-interruptions and frame breaks” ([28], p. 473). McKendy hypothesizes that the psychic trauma inflicted upon those embodying the dual role of victimizer and victimized distorts the individual's relationship to language, thereby complicating the process by which inmates attempt to express themselves and take responsibility for their actions ([28], p. 473). Schuck applies this framework to the understanding of last words, noting that this propensity for 
narrative debris may account for the "inconsistencies, unfinished sentences, and repetitions” ([17], p. 58) found in a great deal of last statements.

Though not stated specifically by Schuck, the implication here is that, though inmates are allowed the opportunity to speak last words and assume responsibility for their crimes, prior life traumas (childhood abuse, the act of committing a murder, ten or more years spent on death row) may intrude and contribute to incoherence [17]. This is a concept further supported by trauma researcher Juliet Mitchell, whose examination of the articulation patterns of survivors of physical and mental traumas revealed the traumatized individual's divorce from language as it is commonly understood [29]. Perhaps the most prominent feature of this divorce from language among the traumatized is the mutation of specific key terms, often privately associated with their trauma but with unknown meaning to others, thus limiting the intellectual or emotional connection the speaker may achieve with any listener [29]. This raises the question of whether those who offer last statements are ever truly heard by others, since some of them, at least, may be speaking a kind of private language.

When considering theories of narrative debris and the divorce from language, it is important to keep in mind that last statements are uttered in the death chamber under conditions of extreme stress. The offender, newly arrived from death row, is tied down to a gurney after an elaborate and sometimes painful process of inserting catheters, surrounded by witnesses that likely include the loved ones of his or her victim, and is confronted with the specter of imminent death [22]. These conditions would have a rattling effect on anyone attempting to speak. In other words, the inconsistencies and digressions characterizing many last statements may derive from many sources other than, or in addition to, those theorized by McKendy and Mitchell [28,29].

As can be seen, the theoretical frameworks currently used to understand the last words of executed inmates, though viable in part, are incomplete. A particular weakness of these theories is their failure to anticipate and explain the nearly $25 \%$ of inmates who choose not to give a statement prior to execution. This weakness also affects the statistics presented, as nearly all of the reviewed content analyses intentionally remove from consideration cases in which inmates did not offer a statement. Given that the opportunity to offer last statements is the last ostensible chance for agency or expression in the lives of the condemned, silence in these moments suggests a profound alienation from the process, which they protest with their silence. More troubling, this silence brings to mind the horrible specter that, long silent on death row, they are now "made mute by the unspeakable cruelty of the killing process” ([4]; [22], p. 112).

\section{Content and Context: Death Row Confinement and the Meaning of Last Words}

The qualitative analysis of the content of last words reported by Vollum and Longmire is unique in that it is both thorough and plausibly related to the lives offenders have led on death row before their fateful consignment to the death chamber [30]. Listed from most to least frequent, the themes reported by Vollum and Longmire are: well-wishes and love, religion, contrition, gratitude, personal reconciliation, denial of responsibility, criticism of the death penalty, anger and resentment, resignation, and accountability ([30], p. 10). One is left with the distinct impression that, for most of the prisoners, last words are a farewell speech to wronged parties, in which the condemned prisoners wish others well, offer an apology to all concerned parties, then hope to go gladly on their journey (even if this is an 
unusual journey), expecting to find a better life (mostly featuring the afterlife), and for all of this they are grateful and, they hope, reconciled with the world.

As noted by the authors, in stark contrast to the popularly held perceptions of death row inmates as evil, remorseless, and irredeemable, this analysis shows changed, reformed men ([30], p. 23). Thoughtfully connecting indications of growth and transformation with the process of offender reform, Vollum and Longmire claim that by executing those who have demonstrated significant personal growth and changed their lives, crucial opportunities are missed to "harness the transformative forces experienced by those on death row and offer them to offenders who will not be executed” ([30], p. 24). In this rendering, last words point to the need to fundamentally rethink the punishment process.

It seems entirely likely that the transformations noted by Vollum and Longmire do in fact occur, though the process by which that change occurs is not fully specified [30]. We suggest that the transformation process can be best understood by examining the dominant contours of the death row experience, the most recent formative experience in the lives of these prisoners. Research on the conditions of death row confinement indicate that states in which executions are carried out on a regular basis, like Texas, have death row regimes that, again like Texas, entail what amounts to extended solitary confinement [16,31]. Research on the experience of death row confinement on such solitary-confinement-style death rows, in turn, reveals a distinctive pattern of widespread demoralization in the face of objectively dehumanizing conditions [5]. That demoralization is the culmination of conditions of confinement that leave prisoners feeling powerless, vulnerable, and alone, a cumulative pattern of effects captured in the notion that death row is a living death and the prisoners are the living dead. Stated differently, prisoners maintained on death row exist rather than live in a recognizably human way [5,32,33].

These findings, drawn primarily from ethnographic work, are useful in assessing the frame of mind of offenders entering the death chamber, drawing on an informed sociological imagination. By this reckoning, the condemned emerge from the closed and oppressive world of death row, where many have been haunted for years by the specter of execution in their dreams and in their reveries, and now, finally, enter the death chamber under the control of the execution team. They are predictably defeated men, men worn down by time and pressure and isolation on death row [6]. These men are very different from the rambunctious, rebellious, and sometimes unrestrainedly violent men who entered death row years earlier, many of them at that juncture threatening to resist execution violently if and when their time came. Then, back at the beginning of their sentence, they typically spoke in anger-against the death penalty as applied to them, against arbitrariness and racism, against rank injustice [5]. They lived hard lives and nursed hard feelings. Now, after years in the crucible of death row, a sizeable number are mute, giving no last words; described by execution team officers as "walking dead men”, they appear to be struggling to hold themselves together simply to get through the execution process [6]. Most prisoners speak, to be sure, but often that speech is rambling and even incoherent, presumably a product of deterioration over time on death row (a common effect), as well as consequence of limited contact on death row with others who are willing to talk with them and engage them as human beings.

Virtually all prisoners in the death chamber are passive; they are "humble men", to quote one execution team officer, who comply meekly with orders, follow routine mechanically, and offer no physical or other resistance to the killing process [6]. Of the 1350 prisoners put to death since 1976, 
one or perhaps two prisoners offered physical resistance. This submissiveness from prisoners considered by many to be "the worst of the worst" [34] is perhaps the main contribution of death row confinement to the execution process, in effect grooming condemned prisoners for the death house, much as anticipated in the classic work of Albert Camus [35] (see also [5-7]). A deeper manifestation of this pervasive passivity, also rooted in the death row experience, we suggest, is the often contrite acceptance of the traditional social meanings associated with the execution, expressed in last words that reflect, not the violence of wild, often psychopathic men, but the tame, civil sentiments of religion, culpability, remorse, the desire for forgiveness, and even gratitude that have been treated decently by others, notably officers and relatives.

To suggest that death row prisoners have been tamed, as it were, and as a consequence speak in terms of the moral sentiments we as a society would like to hear, is not to say that these sentiments are insincere or superficial, mere tropes that have no deeper resonance [4]. It is more accurate to say they are now creatures of confinement, which brings with it a certain sensibility. Long-term captivity such as that found on death row necessarily entails adaptation to a world of conformity, a life of surface routines that allows countless hours of introspection, indeed may make introspection inevitable [36]. In this basic way, the founders of the penitentiary were on to something with their focus on isolation as a goad to introspection. Time and solitude promote change among those who survive the crucible of close imprisonment. Research on lifers, who, like death row prisoners, spend years and even decades in close confinement, reveals that many if not most of these prisoners come to an awareness of the horror of their crimes [37]. This awareness may be even more prevalent on death row, a harsher, more isolated setting offered as punishment for even more profoundly brutal crimes than is normally the case with lifers. Like lifers, who typically comply with prison routines and often yearn to make amends for the harms they have caused [38,39], many condemned prisoners may enter the death chamber not only as passive participants in their own demise, but also as people profoundly aware of the enormity of their crimes, which in turn promotes genuine contrition, remorse, and the associated hope of redemption.

Changed in ways suggested by Vollum and Longmire [30], it is our contention that condemned prisoners yearn to be seen as people, not monsters; yearn to be seen as changed men, men of substance, men different from those who committed horrible crimes, men whose lives, once a wasteland of violence, have now been redeemed. Religion, remorse, contrition, and redemption, in turn, bring in their wake the otherwise counterintuitive notion of gratitude, common among those who speak last words. Moments of decency and compassion-from loved ones who attend the execution to offer support and from correctional officers on the execution team who treat them with civility - stand in sharp and welcome contrast to their lonely lives on death row, where many report feeling abandoned by loved ones and neglected, if not abused, by death row officers [5]. Similarly, decency and civility in the death house stand in sharp and welcome contrast to the treatment one might reasonably expect, given the often breathtakingly brutal crimes that brought these men to the death house. Execution team officers are well aware of the prisoners' crimes and view inmates as responsible for their own executions, noting that their crimes are "forcing the hand of the state," and, indeed, that the prisoners 
"put themselves here by what they did". ${ }^{3}$ The gratitude many prisoners express in their last words, then, is framed against an awareness of loss born of years of suffering on death row, together with a hard-won awareness of the enormity of the crimes they committed and the almost inestimable collateral damage those crimes left in their wake. Condemned prisoners could well be abandoned at the end by loved ones and treated with contempt by staff. It would appear that they are understandably grateful that this is not their fate.

\section{Conclusions}

The analysis reported here suggests a new way of framing the findings of research on the meaning of last words, and points to new lines of research that broaden the context against which last words are understood. That research would include contextual factors, not only taking into account the experience of death row confinement, but also the study of individual histories that precede death row confinement, richly available in mitigation reports [40]. Other communications by condemned prisoners, such as found in diaries or letters, may allow researchers to more directly situate last words in the context of the prisoners' lives on death row. Future research can also examine situational factors in the death chamber that may influence the delivery of last words, such as speaking while strapped to a gurney, speaking to three audiences of witnesses, and, we might imagine, speaking to posterity as well, since these words are recorded and shared with the world, becoming part of the prisoner's legacy [4,22].

The last words of prisoners who were confined in less oppressive death rows can also be scrutinized to see if different themes emerge or if the themes reported to date emerge at different rates among those exposed to different regimes of confinement under sentence of death. Last words that express more defiant themes, though comparatively uncommon [30], may warrant close scrutiny in future work; prisoners who condemn the system or protest their innocence may have made more active adaptations to death row than is the norm, or may have used the notoriety of their death sentences to maintain a more vigorous individuality than is the norm on death row, helping them resist the more socially acceptable scripts so widely reflected in the last words of condemned prisoners on the threshold of execution. ${ }^{4}$ Research can also focus on the extent to which last words are influenced by the legal consciousness of condemned prisoners - their fundamental beliefs about the justice system, which may affect their experiences and adjustments on death row [41,42]. Finally, on the practical side, following Vollum and Longmire, research can be done on how last words might be used to suggest correctional reforms, with an eye to enhancing the prospects for human expression in the prison as well as in the death house.

\section{Acknowledgements}

We thank the anonymous reviewers for thoughtful comments and suggestions for future research.

3 Personal communication, Jerry Givens, retired member of the Virginia execution team, who spoke to a class of students at American University in the spring of 2013; this observation is also confirmed in the documentary, Inside Death Row, a thoughtful rendering of the execution process in Texas.

4 We thank one of the anonymous reviewers for suggesting this line of analysis. 


\section{Author Contributions}

Robert Johnson was primarily responsible for synthesizing the review of prior literature, and for developing and articulating the theoretical perspective that frames the article. L. Caitlin Kanewseke was primarily responsible for reviewing existing literature and describing the key themes examined in prior work. Maya Barak was primarily responsible for reviewing the article and suggesting modifications to create a more cohesive work of scholarship. Kanewske and Barak also made contributions to the overall critique of existing theoretical frameworks, as well as to the discussion of directions for future research.

\section{Conflicts of Interest}

The authors declare no conflict of interest.

\section{References and Notes}

1. Kevin O’Neill. “Muzzling Death Row Inmates: Applying the First Amendment to Regulations That Restrict a Condemned Prisoner’s Last Words.” Arizona State Law Journal 33 (2001): 1159-218.

2. Robert Johnson. “A Few Words on Last Words of Condemned Prisoners.” Journal of Prisoners on Prisons 22, no. 1 (2013): 112-21.

3. Daniel LaChance. "Last words, last meals, and last stands: Agency and individuality in the modern execution process.” Law \& Social Inquiry 32, no. 3 (2007): 701-24.

4. Linda Ross Meyer. “The Meaning of Death: Last Words, Last Meals.” In Who Deserves to Die: Constructing the Executable Subject. Edited by Austin Sarat and Karl Shoemaker. Boston, MA: University of Massachusetts Press, 2011, pp. 176-206.

5. Robert Johnson. Condemned to Die: Life Under Sentence of Death. Prospect Heights, IL: Waveland Press, 1989.

6. Robert Johnson. Death Work: A Study of the Modern Execution Process, 2nd ed. Belmont, CA: Wadsworth, 1998.

7. Mona Lynch. “The disposal of inmate \#85271: Notes on a routine execution.” Studies in Law, Politics, and Society 20 (2000): 3-34.

8. Vic Gatrell. The Hanging Tree: Execution and the English People 1770-1868. Oxford: Oxford University Press, 1994.

9. Lorne Conquergood. "Lethal theatre: Performance, punishment, and the death penalty." Theatre Journal 54, no. 3 (2002): 339-67.

10. Charles Spear. Essays on the Punishment of Death. Littleton, CO: Fred B. Rothman. Co., 1994.

11. Nathan Heflick. "Sentenced to die: Last statements and dying on death row." OMEGA—Journal of Death and Dying 51, no. 4 (2005): 323-36.

12. David Lester, and John Gunn, III. "Ethnic Differences in the Statements Made by Inmates About to be Executed in Texas.” Journal of Ethnicity in Criminal Justice 11, no. 4 (2013): 295-301.

13. Neal Slone, Leo Barrile, Pamela Donovan, Nicole Cotterman, and Angela Smith. "Their dying words: Analyzing the last statements of executed offenders.” Paper presented at the annual meetings of the American Society of Criminology, Chicago, IL, USA, 20 November 2002. 
14. Bryan Misshore, and Christopher Bond. “Last statement.” Unpublished Manuscript, 2007.

15. Kevin Early. Religion and Suicide in the African American Community. Westport, CT: Greenwood, 1992.

16. Dave Mann. “Solitary Men: Does prolonged isolation drive death row prisoners insane?” Texas Observer, 10 November 2010. http://www.texasobserver.org/cover-story/solitary-men.

17. Andreas Schuck, and Janelle Ward. "Dealing with the inevitable: Strategies of self-presentation and meaning construction in the final statements of inmates on Texas death row." Discourse \& Society 19, no. 1 (2008): 43-62.

18. Judy Eaton, and Anna Theuer. "Apology and Remorse in the Last Statements of Death Row Prisoners.” Justice Quarterly 26, no. 2 (2009): 327-47.

19. Holley Hodgins, and Elizabeth Liebeskind. "Apology versus defense: Antecedents and consequences.” Journal of Experimental Psychology 39 (2003): 297-316.

20. Stephen Rice, Danielle Dirks, and Julie Exline. "Of Guilt, Defiance, and Repentance: Evidence from the Texas Death Chamber.” Justice Quarterly 26, no. 2 (2009): 295-326.

21. John Braithwaite, and Stephen Mugford. "Conditions of successful reintegration ceremonies: Dealing with juvenile offenders.” British Journal of Criminology 34 (1994): 139-71.

22. Robert Johnson, Sandra McGunigall-Smith, and Claire Callahan. "Can I Get a Witness? Thoughts on Witnessing Executions.” The Prison Journal 93, no. 1 (2013): 11-33.

23. Ernest Becker. The Denial of Death. New York, NY: Free Press, 1973.

24. Sheldon Solomon, Jeff Greenberg, and Tom Pyszczynski. "Terror Management Theory of Self-Esteem.” In Handbook of Social and Clinical Psychology: The Health Perspective. Edited by Charles Snyder and Donelson Forsyth. New York, NY: Pergamon Press, 1991, pp. 21-40.

25. Sheldon Solomon, Jeff Greenberg, and Tom Pyszczynski. “The Cultural Animal: Twenty Years of Terror Management Theory and Research.” In Handbook of Experimental Existential Psychology. Edited by Jeff Greenberg, Sander Koole and Tom Pyszczynski. New York, NY: Guilford Press, 2004, pp. 13-34.

26. Jamie Arndt, Clay Routledge, Cathy Cox, and Jamie Goldenberg. "The Worm at the Core: A Terror Management Perspective on the Roots of Psychological Dysfunction.” Applied and Preventative Psychology 11 (2005): 191-213.

27. John Jost, Grainne Fitzsimons, and Aaron Kay. "The ideological animal: A system justification view.” In Handbook of Experimental Existential Psychology. Edited by Jeff Greenberg, Sander Koole and Thomas Pyszcynski. New York, NY: The Guilford Press, 2004, pp. 263-83.

28. John McKendy. “'I'm very careful about that': Narrative and agency of men in prison.” Discourse \& Society 17, no. 4 (2006): 473-502.

29. Juliet Mitchell. “Trauma, recognition, and the place of language.” Diacritics 28, no. 4 (1998): 121-33.

30. Scott Vollum, and Dennis Longmire. "Giving voice to the dead: Last statements of the condemned.” Contemporary Justice Review 12, no. 1 (2009): 5-26.

31. Robert Johnson, and Harmony Jovet. "Life under Sentence of Death: Historical and Contemporary Perspectives.” In America's Experiment with Capital Punishment: Reflections on the Past, Present, and Future of the Ultimate Penal Sanction, 3rd ed. Edited by James Acker, Robert Bohm and Charles Lanier. Durham, NC: Carolina Academic Press, 2014. 
32. Lloyd Vogelman. “The Living Dead: Living on Death Row.” South African Journal on Human Rights 5 (1989): 183-95.

33. Diana Peel. "Clutching at Life, Waiting to Die: The Experience of Death Row Incarceration.” Western Criminology Review 14, no. 3 (2013): 61-72.

34. Robert Blecker. The Death of Punishment: Searching for Justice among the Worst of the Worst. New York, NY: Palgrave Macmillan, 2013.

35. Albert Camus. "Reflections on the Guillotine." In Resistance, Rebellion, and Death. Edited by Albert Camus. New York, NY: Knopf, 1969, p. 205.

36. Robert Johnson. Hard Time: Understanding and Reforming the Prison, 3rd ed. Belmont, CA: Wadsworth, 2001.

37. John Irwin. Lifers: Seeking Redemption in Prison. New York, NY: Routledge, 2009, pp. 94-95.

38. Robert Johnson, and Ania Dobrzanska. "Mature coping among life-sentence prisoners: An exploratory study of adjustment dynamics.” Corrections Compendium 30, no. 6 (2005): 8-38.

39. Robert Johnson, and Sandra McGunigall-Smith. "Life Without Parole, America’s Other Death Penalty: Notes on Life Under Sentence of Death by Incarceration.” The Prison Journal 88, no. 2 (2008): 328-46.

40. Craig Haney. "Evolving Standards of Decency: Advancing the Nature and Logic of Capital Mitigation.” Hofstra Law Review 36, no. 3 (2008): 835-82.

41. Patricia Ewick, and Susan S. Silbey. The Common Place of Law: Stories from Everyday Life. Chicago, IL: University of Chicago Press, 1998.

42. Sally Engle Merry. Getting Justice and Getting Even: Legal Consciousness Among Working-Class Americans. Chicago, IL: University of Chicago Press, 1990.

(C) 2014 by the authors; licensee MDPI, Basel, Switzerland. This article is an open access article distributed under the terms and conditions of the Creative Commons Attribution license (http://creativecommons.org/licenses/by/3.0/). 